\title{
STUDI KOMITMEN DAN KINERJA KEPEMIMPINAN PEJABAT STRUKTURAL DI RSUD dr. R. SOEDARSONO KOTA PASURUAN
}

\author{
Andina Erika Risfianty*, Karjono* \\ *Prodi Administrasi Rumah Sakit STIKES Yayasan Rumah Sakit Dr. Soetomo Surabaya, \\ Email:andinaerika@gmail.com
}

\begin{abstract}
ABSTRAK
Untuk mengukur kualitas manajemen dan kepemimpinan di rumah sakit salah satunya dengan cara mengukur tingkat efektifitas organisasi melalui pengukuran efektifitas pelaksanaan tugas pokok dan fungsi pejabat struktural. Penelitian ini bertujuan untuk menganalisis aspek komitmen kepemimpinan terhadap tingkat efektifitas organisasi dan menganalisis aspek kinerja kepemimpinan pejabat struktural. Penelitian ini merupakan penelitian deskriptif yang melibatkan 13 pejabat struktural di RSUD dr. R. Soedarsono sebagai subyek penelitian. Pengumpulan data menggunakan kuesioner untuk mengetahui komitmen dan wawancara serta penelusuran dokumen pelaksanaan tugas pokok dan fungsi untuk mengetahui tingkat efektifitas organisasi. Kinerja pejabat struktural dilihat dari pelaksanaan leadership roles sebagai kunci kompetensi seorang pemimpin dengan memetakan aktifitas menurut tugas pokok dan fungsi. Kemudian melihat hasil dari kinerja pejabat struktural yaitu pengukuran indeks kepuasan masyarakat dan indeks kepuasan karyawan. Hasil Komitmen afektif, komitmen kelanjutan dan komitmen normatif pada Eselon III dan Eselon IV memiliki tingkatan yang berbeda. Komitmen atau kesediaan untuk bertahan dari 3 bidang 1 bagian, hanya dirasakan oleh Bidang Pelayanan, sedangkan 2 bidang 1 bagian lainnya dalam kategori yang rendah. Komitmen secara keseluruhan pejabat struktural di RSUD dr. R. Soedarsono terhadap organisasi berada pada kategori yang rendah. Kinerja pejabat struktural masih belum mencapai $100 \%$ karena peran dan aktivitasnya menurut tugas pokok dan fungsi yang di emban, belum sepenuhnya dilaksanakan. Kinerja pejabat struktural juga bisa dilihat dari pencapaian indeks kepuasan masyarakat yang didapati sebesar $70,79 \%$ dan indeks kepuasan karyawan sebesar 53,17\%. Tingkat efektifitas organisasi mencapai $87,53 \%$. Kesimpulan dari penelitian ini adalah untuk meningkatkan efektifitas organisasi, pihak pejabat struktural diharapkan lebih memahami peran dan aktifitas berdasarkan tugas pokok dan fungsi yang di emban masing-masing.
\end{abstract}

Kata Kunci : Komitmen, Kinerja, Tingkat Efektifitas Organisasi

\section{Abstract}

To measure management quality and leadership in the hospital (performance leadership and management), one way to measure the effectiveness of the organization through the measurement of the effectiveness of structural officials duties and functions. This study aimed to analyze the aspects of leadership commitment on the effectiveness of the organization and analyze the performance aspects of leadership of the structural officials. This research is a descriptive study involving 13 structural officials $d r$. R. Sudarsono Regional Public Hospital as research subjects. Collecting data uses a questionnaire to determine the commitment, and interviews and document tracking the implementation of the basic tasks and functions to determine the level of effectiveness of the organization. 
Performance structural officials can be seen from the implementation of leadership roles as a key competence of a leader by mapping the activity according to the duties and functions. Then look at the performance impact of structural officials are measuring community satisfaction index and the index of employee satisfaction. Results affective commitment, continuance commitment and normative commitment on Echelon III and Echelon IV have different levels. Therefore, the effectiveness of the organization has not reached $100 \%$. Commitment or willingness to endure the three field's one part, only felt by the Service Field, while the other two areas of one part are in a low category. Commitment overall of structural officials in dr. R. Sudarsono Regional Public Hospital on organizations are in a lower category. Performance structural officer have not reached $100 \%$ because of the role and activities in accordance with the basic tasks and functions being carried, have not yet fully implemented. Possibly due to structural officials who do not understand the basic tasks and functions of the waistband respectively. Performance structural officers can be seen also from the achievement of community satisfaction index which is found at $70.79 \%$ and the employee satisfaction index by 53.17\%. The effectiveness degree of organitation reaches $87,53 \%$. The conclusion of this study is to improve the effectiveness of the organization, the structural officials are expected to better understand the role and activities based on the duties and functions that being carried respectively.

Keywords : Commitment, Performance, Organizational Effectiveness Level

\section{PENDAHULUAN}

Perkembangan ilmu manajemen dan kepemimpinan di rumah sakit dalam dasawarsa terakhir telah berkembang dengan pesat. Sebagai organisasi nirlaba dan bersifat sosial dalam bidang pelayanan maka dibutuhkan kemampuan manajemen dan kepemimpinan yang spesifik sesuai dengan ciri organisasi rumah sakit. Atas dasar ini setiap rumah sakit perlu memperhatikan dan menerapkan ilmu-ilmu manajemen dan kepemimpinan secara baik dan konsisten untuk mewujudkan tujuan rumah sakit. Untuk mengukur kualitas manajemen dan kepemimpinan di rumah sakit (performance leadership and management) salah satunya dengan cara mengukur tingkat efektifitas organisasi melalui pengukuran efektifitas pelaksanaan tugas pokok dan fungsi pejabat struktural.

\section{METODE}

Penelitian ini berupa peneilitian deskriptif, yang bertujuan menggambarkan situasi-kondisi mengenai komitmen dan kinerja kepemimpinan untuk meningkatkan efektifitas organisasi berdasarkan tugas pokok dan fungsi yang dilaksanakan oleh 13 orang pejabat struktural di RSUD dr. R. Soedarsono, Kota Pasuruan. Instrumen penelitian ini menggunakan teknik wawancara dan penelusuran dokumen yang dilakukan dengan menggunakan alat bantu matrik tugas pokok dan fungsi, kuesioner untuk mengetahui informasi tentang komitmen kepemimpinan serta dokumen pencapaian kinerja pejabat struktural. Data primer diperoleh dari matrik pelaksanaan tugas pokok dan fungsi serta kuesioner untuk pengukuran komitmen. Data sekunder diperoleh dari data pencapaian perjanjian kinerja pejabat struktural RSUD dr. R. Soedarsono, Kota Pasuruan.

\section{HASIL}

Tabel 1 Identitas Responden Berdasarkan Kelompok Usia

\begin{tabular}{|c|c|c|c|}
\hline $\begin{array}{c}\text { USIA } \\
\text { RANGE }\end{array}$ & JABATAN & $\begin{array}{c}\text { FRE } \\
\text { KUENSI }\end{array}$ & $\begin{array}{c}\text { PERSENTASE } \\
(\%)\end{array}$ \\
\hline $\begin{array}{c}46-50 \\
\text { Tahun }\end{array}$ & \multirow{2}{*}{$\begin{array}{c}\text { ESELON } \\
\text { III }\end{array}$} & 2 & 50 \\
\cline { 1 - 1 } $\begin{array}{c}51-55 \\
\text { Tahun }\end{array}$ & 2 & 50 \\
\hline \multicolumn{2}{|c|}{ TOTAL } & $\mathbf{4}$ & $\mathbf{1 0 0}$ \\
\hline $\begin{array}{c}30-35 \\
\text { Tahun }\end{array}$ & $\begin{array}{c}\text { ESELON } \\
\text { IV }\end{array}$ & 1 & 11,1 \\
\hline
\end{tabular}




\begin{tabular}{|c|c|c|c|}
\hline $\begin{array}{c}\text { USIA } \\
\text { RANGE }\end{array}$ & JABATAN & $\begin{array}{c}\text { FRE } \\
\text { KUENSI }\end{array}$ & $\begin{array}{c}\text { PERSENTASE } \\
(\%)\end{array}$ \\
\hline $\begin{array}{l}\text { 41-45 } \\
\text { Tahun }\end{array}$ & & 1 & 11,1 \\
\hline $\begin{array}{l}\text { 46-50 } \\
\text { Tahun }\end{array}$ & & 4 & 44,4 \\
\hline $\begin{array}{l}51-55 \\
\text { Tahun }\end{array}$ & & 3 & 33,3 \\
\hline \multicolumn{2}{|c|}{ TOTAL } & 9 & 100 \\
\hline
\end{tabular}

Sumber : Diolah dari Data Primer Kuesioner Komitmen Organisasi

Responden dalam penelitian ini dapat dideskripsikan bahwa pada pada Eselon III terdapat kelompok usia 46-50 tahun yang berjumlah 2 orang atau sama dengan 50\%, kelompok usia 51-55 tahun berjumlah 2 orang atau sama dengan $50 \%$. Pada Eselon IV untuk usia antara 30-55 tahun berjumlah 1 orang atau sama dengan $11,1 \%$, usia antara 41-45 tahun berjumlah 1 orang atau sama dengan $11,1 \%$, 46-50 tahun berjumlah 4 orang atau sama dengan $44,4 \%$, dan 51-55 tahun berjumlah 3 orang atau sama dengan $33,3 \%$.

Tabel 2 Identitas Responden Berdasarkan Lama Bekerja di Bidangnya

\begin{tabular}{|c|c|c|c|}
\hline $\begin{array}{c}\text { Lama } \\
\text { Kerja di } \\
\text { Bidang } \\
\text { nya }\end{array}$ & JABATAN & $\begin{array}{c}\text { FRE } \\
\text { KUENSI }\end{array}$ & $\begin{array}{c}\text { PERSENTASE } \\
(\%)\end{array}$ \\
\hline $\begin{array}{c}1-5 \\
\text { Tahun }\end{array}$ & $\begin{array}{c}\text { ESELON } \\
\text { III }\end{array}$ & 4 & 100 \\
\hline $\begin{array}{c}1-5 \\
\text { Tahun }\end{array}$ & \multirow{2}{*}{$\begin{array}{c}\text { ESELON } \\
\text { IV }\end{array}$} & 7 & 77,8 \\
\cline { 1 - 4 } $\begin{array}{c}\text { 6-10 } \\
\text { Tahun }\end{array}$ & 2 & 22,2 \\
\hline \multicolumn{2}{|c|}{ Sumber: }
\end{tabular}
Komitmen Organisasi.

Berdasarkan lama bekerja di bidangnya, responden dalam penelitian ini dapat didiskripsikan bahwa responden pada Eselon III yang bekerja selama 1-5 tahun sebanyak 4 orang atau $100 \%$, pada Eselon IV sebanyak 7 orang atau $77,8 \%$, sisanya bekerja selama 7 tahun sebanyak 2 orang 22,2\%. Dapat disimpulkan responden yang bekerja dibidangnya dengan persentase tertinggi adalah 1-5 tahun yang terdapat pada Eselon IV.
Tabel 3 Hasil Tingkat Komitmen pada Eselon III dan Eselon IV

\begin{tabular}{|c|c|c|c|c|}
\hline Jabatan & $\begin{array}{c}\text { Komit } \\
\text { men } \\
\text { Afektif }\end{array}$ & $\begin{array}{c}\text { Komitmen } \\
\text { Berkelanjut } \\
\text { an }\end{array}$ & $\begin{array}{c}\text { Komit } \\
\text { men } \\
\text { Norma } \\
\text { tif }\end{array}$ & $\begin{array}{c}\text { Komit } \\
\text { men } \\
\text { Organi } \\
\text { sasi }\end{array}$ \\
\hline $\begin{array}{c}\text { Eselon } \\
\text { III }\end{array}$ & $\begin{array}{c}2.65- \\
\text { Cukup } \\
\text { Tinggi }\end{array}$ & $\begin{array}{c}1.96- \\
\text { Rendah }\end{array}$ & $\begin{array}{c}2.43- \\
\text { Rendah }\end{array}$ & $\begin{array}{c}2.34- \\
\text { Rendah }\end{array}$ \\
\hline $\begin{array}{c}\text { Eselon } \\
\text { IV }\end{array}$ & $\begin{array}{c}3.16- \\
\text { Cukup } \\
\text { Tinggi }\end{array}$ & Rendah & $\begin{array}{c}2.08- \\
\text { Cukup } \\
\text { Tinggi }\end{array}$ & $\begin{array}{c}2.63- \\
\text { Cukup } \\
\text { Tinggi }\end{array}$ \\
\hline
\end{tabular}

Sumber: Diolah dari Data Primer Kuesioner Komitmen Organisasi

Eselon III memiliki komitmen afektif cukup tinggi, komitmen kelanjutan rendah, komitmen rendah. Responden pada profil ini akan bertahan dalam organisasi karena karena memang keinginannya untuk tetap bertahan berada diorganisasi. menikmati keanggotaannya dan juga bertahan bukan karena tidak adanya pilihan kerja di tempat lain maupun rasa tanggung jawab terhadap organisasi, melainkan kedekatan antar rekan kerja yang kemudian menciptakan keterikatan emosional karena setuju dan mempercayai misi, tujuan dan nilai-nilai organisasi yang dijalankan.

Eselon IV komitmen afektif cukup tinggi, komitmen kelanjutan rendah, komitmen cukup tinggi. Responden pada profil ini memiliki penghayatan yang positif terhadap organisasi dan dapat dengan mudah menerima aturan dan kebijakan organisasi. Bagi responden finansial bukan alasan utama mereka bekerja di RSUD dr. R. Soedarsono. Responden juga merasakan adanya suatu kewajiban dan tugas untuk bertahan dalam organisasi dan memiliki kecenderungan untuk mematuhi peraturan yang ada. Responden akan merasa bersalah bila melanggar aturan karena responden tidak ingin memberikan dampak yang buruk bagi organisasi.

Tabel 4 Hasil Tingkat Komitmen 3 Bidang dan 1 Bagian di RSUD dr. R. Soedarsono 


\begin{tabular}{|c|c|c|c|c|}
\hline \multirow{2}{*}{$\begin{array}{l}\text { Bidang/ } \\
\text { Bagian }\end{array}$} & KA & KB & $\mathrm{KN}$ & \multirow{2}{*}{$\begin{array}{c}\text { Komitmen } \\
\text { organisasi }\end{array}$} \\
\hline & \multicolumn{3}{|c|}{ Nilai Rerata } & \\
\hline $\begin{array}{c}\text { Bidang } \\
\text { pelayanan }\end{array}$ & $\begin{array}{l}3.31- \\
\text { Cukup } \\
\text { Tinggi }\end{array}$ & $\begin{array}{l}2.08- \\
\text { Rendah }\end{array}$ & $\begin{array}{l}2.45- \\
\text { Cukup } \\
\text { Tinggi }\end{array}$ & $\begin{array}{l}2.61- \\
\text { Cukup } \\
\text { Tinggi }\end{array}$ \\
\hline $\begin{array}{c}\text { Bidang } \\
\text { Keperawa } \\
\tan \end{array}$ & $\begin{array}{l}3.08- \\
\text { Cukup } \\
\text { Tinggi }\end{array}$ & $\begin{array}{l}1.87- \\
\text { Rendah }\end{array}$ & $\begin{array}{l}2.62- \\
\text { Cukup } \\
\text { Tinggi }\end{array}$ & $\begin{array}{c}2.52- \\
\text { Rendah }\end{array}$ \\
\hline $\begin{array}{c}\text { Bidang } \\
\text { Pengemb } \\
\text { angan dan } \\
\text { Pengadu } \\
\text { an }\end{array}$ & $\begin{array}{l}2.66- \\
\text { Cukup } \\
\text { Tinggi }\end{array}$ & $\begin{array}{l}2.20- \\
\text { Rendah }\end{array}$ & $\begin{array}{l}2.62- \\
\text { Cukup } \\
\text { Tinggi }\end{array}$ & $\begin{array}{c}2.49- \\
\text { Rendah }\end{array}$ \\
\hline $\begin{array}{c}\text { Bagian } \\
\text { Tata } \\
\text { Usaha }\end{array}$ & $\begin{array}{l}2.96- \\
\text { Cukup } \\
\text { Tinggi }\end{array}$ & $\begin{array}{c}2.03- \\
\text { Rendah }\end{array}$ & $\begin{array}{l}2.62- \\
\text { Cukup } \\
\text { Tinggi }\end{array}$ & $\begin{array}{c}2.53- \\
\text { Rendah }\end{array}$ \\
\hline \multicolumn{4}{|c|}{ Akumulasi Keseluruhan } & $\begin{array}{c}2.53- \\
\text { Rendah }\end{array}$ \\
\hline
\end{tabular}

Bidang Pelayanan, Bidang Keperawatan, Bidang Pengembangan dan Pengaduan, Bagian Tata Usaha memiliki komitmen afektif dengan kategori cukup tinggi, komitmen berkelanjutan yang rendah dan komitmen normatif yang cukup tinggi. Responden pada profil ini memiliki penghayatan yang positif terhadap organisasi dan dapat dengan mudah menerima aturan dan kebijakan organisasi. Bagi responden finansial bukan alasan utama mereka bekerja di RSUD dr. R. Soedarsono. Responden juga merasakan adanya suatu kewajiban dan tugas untuk bertahan dalam organisasi dan memiliki kecenderungan untuk mematuhi peraturan

Tabel 6 Tingkat Efektifitas Pelaksanaan Tugas Pokok dan Fungsi Eselon IV di RSUD dr. R. Soedarsono yang ada. Responden akan merasa bersalah bila melanggar aturan karena responden tidak ingin memberikan dampak yang buruk bagi organisasi. Dengan demikian, hasil akumulasi keseluruhan kesediaan untuk bertahan di organisasi hanya dirasakan oleh bidang pelayanan dan komitmen keseluruhan bidang/bagian termasuk dalam kategori yang rendah.

Tabel 5 Tingkat Efektifitas Pelaksanaan Tugas Pokok dan Fungsi Eselon III di RSUD dr. R. Soedarsono

\begin{tabular}{|c|c|c|c|c|}
\hline \multirow{2}{*}{$\begin{array}{c}\text { Tugas } \\
\text { Pokok } \\
\text { dan }\end{array}$} & \multirow{2}{*}{$\begin{array}{c}\text { Aktivitas } \\
\text { Pelaksanaan }\end{array}$} & \multicolumn{2}{|c|}{ Pelaksanaan } & \multirow{2}{*}{$\begin{array}{c}\text { Tingkat } \\
\text { Efektifitas }\end{array}$} \\
\cline { 3 - 4 } Fungsi & TUPOKSI & Sudah & Belum & \\
\hline 7 & 43 & 40 & 3 & $93,02 \%$ \\
\hline 8 & 61 & 56 & 5 & $91,8 \%$ \\
\hline 6 & 29 & 23 & 6 & $79,3 \%$ \\
\hline 6 & 58 & 32 & 26 & $55,17 \%$ \\
\hline $\mathbf{2 7}$ & $\mathbf{1 9 1}$ & $\mathbf{1 5 1}$ & $\mathbf{4 0}$ & $\mathbf{7 9 , 0 5 \%}$ \\
\hline
\end{tabular}

Sumber : Diolah dari Data Primer Pelaksanaan Tugas Pokok dan Fungsi Pejabat Struktural

Tabel 5.12 menunjukkan bahwa tingkat efektifitas pelaksanaan tupoksi pada Eselon III mencapai 79,05\%. Persentase tingkat efektifitas yang terendah terdapat pada Kepala Bagian Tata Usaha.

\begin{tabular}{|c|c|c|c|c|}
\hline \multirow{2}{*}{$\begin{array}{c}\text { Tugas Pokok } \\
\text { dan Fungsi }\end{array}$} & \multirow{2}{*}{$\begin{array}{c}\text { Aktivitas } \\
\text { Pelaksanaan } \\
\text { TUPOKSI }\end{array}$} & \multicolumn{2}{|c|}{ Pelaksanaan } & \multirow{2}{*}{$\begin{array}{c}\text { Tingkat } \\
\text { Efektifitas }\end{array}$} \\
\cline { 3 - 4 } & 30 & Sudah & Belum & \\
\hline 10 & 25 & 23 & 7 & $76,67 \%$ \\
\hline 6 & 32 & 31 & 3 & $88 \%$ \\
\hline 7 & 33 & 24 & 9 & $96,8 \%$ \\
\hline 9 & 37 & 28 & 9 & $72,72 \%$ \\
\hline 9 & 23 & 3 & 20 & $75,6 \%$ \\
\hline 7 & 55 & 55 & - & $13,4 \%$ \\
\hline 15 & 17 & 13 & 4 & $760 \%$ \\
\hline 5 & 20 & 18 & 2 & $90 \%$ \\
\hline 7 & $\mathbf{2 7 2}$ & $\mathbf{2 1 7}$ & $\mathbf{5 5}$ & $\mathbf{7 9 , 7 7 \%}$ \\
\hline $\mathbf{7 5}$ & & & 17 & \\
\hline
\end{tabular}

Sumber : Diolah dari Data Primer Pelaksanaan Tugas Pokok dan Fungsi Pejabat Struktural 
Tingkat efektifitas pelaksanaan tupoksi pada Eselon IV mencapai $79,77 \%$.
Kepala seksi yang persentase tingkat efektifitasnya terendah adalah Kepala Seksi Pengaduan dan Informasi.

Tabel 7 Tingkat Efektifitas Pelaksanaan Tugas Pokok dan Fungsi Pejabat Struktural di RSUD dr. R. Soedarsono

\begin{tabular}{|c|c|c|c|c|c|}
\hline \multirow{2}{*}{ Kode Jabatan } & \multirow{2}{*}{$\begin{array}{l}\text { Tugas Pokok } \\
\text { dan Fungsi }\end{array}$} & \multirow{2}{*}{$\begin{array}{c}\text { Aktivitas Pelaksanaan } \\
\text { TUPOKSI }\end{array}$} & \multicolumn{2}{|c|}{ Pelaksanaan } & \multirow{2}{*}{$\begin{array}{c}\text { Tingkat } \\
\text { Efektifitas }\end{array}$} \\
\hline & & & Sudah & Belum & \\
\hline 02. & 7 & 43 & 40 & 3 & $93,02 \%$ \\
\hline 02.1 & 10 & 30 & 23 & 7 & $76,67 \%$ \\
\hline 02.2 & 6 & 25 & 22 & 3 & $88 \%$ \\
\hline Jumlah & 23 & 98 & 85 & 13 & $86,73 \%$ \\
\hline 03 & 8 & 61 & 56 & 5 & $91,8 \%$ \\
\hline 03.1 & 7 & 32 & 31 & 1 & $96,8 \%$ \\
\hline 03.2 & 9 & 33 & 24 & 9 & $72,72 \%$ \\
\hline Jumlah & 24 & 126 & 111 & 15 & $\mathbf{8 8 , 0 9 \%}$ \\
\hline 04 & 6 & 29 & 23 & 6 & $79,3 \%$ \\
\hline 04.1 & 9 & 37 & 28 & 9 & $75,6 \%$ \\
\hline 04.2 & 7 & 23 & 3 & 20 & $13,4 \%$ \\
\hline Jumlah & 22 & 89 & 54 & 35 & $60,67 \%$ \\
\hline 05 & 6 & 58 & 32 & 26 & $55,17 \%$ \\
\hline 05.1 & 15 & 55 & 55 & - & $100 \%$ \\
\hline 05.2 & 5 & 17 & 13 & 4 & $76,47 \%$ \\
\hline 05.3 & 7 & 20 & 18 & 2 & $90 \%$ \\
\hline Jumlah & 27 & 150 & 118 & 32 & $78,67 \%$ \\
\hline $\begin{array}{c}\text { Tingkat } \\
\text { Efektivitas } \\
\text { Organisasi } \\
\text { Rumah Sakit }\end{array}$ & 96 & 463 & 368 & 95 & $\mathbf{7 9 , 4 8 \%}$ \\
\hline
\end{tabular}

Sumber :Diolah dari Data Primer Pelaksanaan Tugas Pokok dan Fungsi Pejabat Struktural RSUD dr. R. Soedarsono

Tabel 5.14, dapat dijelaskan bahwa hasil pengamatan terhadap efektifitas kepemimpinan dalam menjalankan tugas pokok dan fungsi ini belum dilaksanakan sepenuhnya atau belum mencapai $100 \%$ oleh masing-masing pemangku jabatan pada bidang/seksi dan bagian/sub bagian yang terkait. Dari 3 Bidang dan 1 Bagian, tingkat efektifitas yang dilaksanakan oleh Bidang Pelayanan tercapai $86,73 \%$,

Bidang Keperawatan tercapai 88,09\%, Bidang Pengembangan dan Pengaduan tercapai $60,67 \%$, Bagian Tata Usaha tercapai $78,67 \%$ dan tingkat efektifitas organisasi mencapai 79,48\%.Dari 3 bidang dan 1 bagian ini, yang mencapai tingkat efektifitas terendah adalah Bidang Pengembangan dan Pengaduan,yang tertinggi adalah Bidang Keperawatan.
Tabel 8 Tingkat Efektifitas Pelaksanaan Peran Kepemimpinan Pejabat Struktural Eselon III RSUD Dr. R. Soedarsono

\begin{tabular}{|l|c|c|c|}
\hline \multicolumn{1}{|c|}{$\begin{array}{c}\text { Peran } \\
\text { Kepemimpinan }\end{array}$} & Jumlah & Eksistensi & Capaian \\
\hline $\begin{array}{l}\text { R1= Mentor } \\
\text { Role }\end{array}$ & 31 & 27 & $87,09 \%$ \\
\hline $\begin{array}{l}\text { R2 = Facilitator } \\
\text { Role }\end{array}$ & 49 & 41 & $83,67 \%$ \\
\hline $\begin{array}{l}\text { R3= Monitor } \\
\text { Role }\end{array}$ & 23 & 18 & $78,26 \%$ \\
\hline $\begin{array}{l}\text { R4= Co- } \\
\text { ordinator Role }\end{array}$ & 98 & 73 & $74,48 \%$ \\
\hline $\begin{array}{l}\text { R5 = Director } \\
\text { Role }\end{array}$ & 79 & 56 & $70,88 \%$ \\
\hline $\begin{array}{l}\text { R6= Producer } \\
\text { Role }\end{array}$ & 70 & 49 & $70 \%$ \\
\hline R7= Broker Role & 22 & 18 & $81,81 \%$ \\
\hline R8= Innovator & 21 & 20 & $95,23 \%$ \\
\hline \multicolumn{1}{|c|}{ TOTAL } & $\mathbf{3 9 3}$ & $\mathbf{3 0 2}$ & $\mathbf{7 6 , 8 4 \%}$ \\
\hline
\end{tabular}

Sumber: Diolah dari Data Primer Pemetaan Peran Kepemimpinan 
Tingkat efektifitas pelaksanaan peran kepemimpinan pada Eselon III mencapai $76,84 \%$. Capaian pelaksanaan peran kepemimpinan yang paling rendah adalah terletak pada producer role.

Tabel 9 Tingkat Efektifitas Pelaksanaan Peran Kepemimpinan Pejabat Struktural Eselon IV RSUD dr. R. Soedarsono

\begin{tabular}{|l|c|c|c|}
\hline \multicolumn{1}{|c|}{ Peran Kepemimpinan } & Jumlah & Eksistensi & Capaian \\
\hline R1 = Mentor Role & 48 & 32 & $66,67 \%$ \\
\hline R2 = Facilitator Role & 155 & 117 & $75,48 \%$ \\
\hline R3 = Monitor Role & 49 & 46 & $93,87 \%$ \\
\hline R4 = Co-ordinator Role & 105 & 91 & $86,67 \%$ \\
\hline R5 = Director Role & 58 & 42 & $72,41 \%$ \\
\hline R6 = Producer Role & 86 & 77 & $89,53 \%$ \\
\hline R7 = Broker Role & 40 & 33 & $82,5 \%$ \\
\hline R8 = Innovator & 36 & 28 & $77,78 \%$ \\
\hline \multicolumn{1}{|c|}{ TOTAL } & $\mathbf{5 7 7}$ & $\mathbf{4 6 6}$ & $\mathbf{8 0 , 7 6 \%}$ \\
\hline
\end{tabular}

Sumber : Diolah dari Data Primer Pemetaan Peran Kepemimpinan

Tingkat efektifitas pelaksanaan peran kepemimpinan pada Eselon IV mencapai 80,76\%. Capaian pelaksanaan peran kepemimpinan yang paling rendah adalah terletak pada mentor role.

Tabel 10 Tingkat Efektifitas Pelaksanaan Peran Kepemimpinan Pejabat Struktural di RSUD dr. R. Soedarsono

\begin{tabular}{|c|c|c|c|c|}
\hline \multirow{10}{*}{ BIDANG Pelayanan } & Peran Kepemimpinan & Jumlah & Eksistensi & Capaian \\
\hline & R1 = Mentor Role & 12 & 11 & $91,67 \%$ \\
\hline & R2 = Facilitator Role & 41 & 36 & $87,80 \%$ \\
\hline & R3 = Monitor Role & 14 & 14 & $100 \%$ \\
\hline & R4 = Co-ordinator Role & 41 & 35 & $85,36 \%$ \\
\hline & R5 = Director Role & 31 & 24 & $77,41 \%$ \\
\hline & R6 = Producer Role & 17 & 14 & $82,35 \%$ \\
\hline & R7 = Broker Role & 17 & 12 & $70,58 \%$ \\
\hline & R8 = Innovator Role & 15 & 13 & $86,67 \%$ \\
\hline & TOTAL & 188 & 159 & $84,57 \%$ \\
\hline \multirow{10}{*}{$\begin{array}{l}\text { BIDANG } \\
\text { Keperawatan }\end{array}$} & Peran Kepemimpinan & Jumlah & Eksistensi & Capaian \\
\hline & R1 = Mentor Role & 6 & 5 & $83,33 \%$ \\
\hline & $\mathrm{R} 2=$ Facilitator Role & 48 & 40 & $83,33 \%$ \\
\hline & R3 = Monitor Role & 21 & 20 & $95,23 \%$ \\
\hline & $\mathrm{R} 4=$ Co-ordinator Role & 55 & 52 & $94,54 \%$ \\
\hline & R5 = Director Role & 37 & 34 & $91,89 \%$ \\
\hline & R6 = Producer Role & 46 & 38 & $82,60 \%$ \\
\hline & R7 = Broker Role & 14 & 13 & $92,85 \%$ \\
\hline & R8 = Innovator Role & 16 & 13 & $81,25 \%$ \\
\hline & TOTAL & 243 & 215 & $88,47 \%$ \\
\hline \multirow{2}{*}{$\begin{array}{l}\text { BIDANG } \\
\text { Pengembangan dan }\end{array}$} & Peran Kepemimpinan & Jumlah & Eksistensi & Capaian \\
\hline & R1 = Mentor Role & 33 & 18 & $54,54 \%$ \\
\hline
\end{tabular}




\begin{tabular}{|c|c|c|c|c|c|}
\hline \multirow{8}{*}{\multicolumn{2}{|c|}{ Pengaduan }} & R2 = Facilitator Role & 50 & 26 & $52 \%$ \\
\hline & & R3 = Monitor Role & 11 & 9 & $81,81 \%$ \\
\hline & & R4 = Co-ordinator Role & 38 & 26 & $68,42 \%$ \\
\hline & & R5 = Director Role & 29 & 18 & $62,06 \%$ \\
\hline & & R6 = Producer Role & 14 & 9 & $64,28 \%$ \\
\hline & & R7 = Broker Role & 7 & 5 & $71,42 \%$ \\
\hline & & R8 = Innovator & 7 & 5 & $71,42 \%$ \\
\hline & & TOTAL & 189 & 116 & $61,37 \%$ \\
\hline \multirow{10}{*}{$\begin{array}{l}\text { BAGIAN } \\
\text { Usaha }\end{array}$} & \multirow{10}{*}{ Tata } & Peran Kepemimpinan & Jumlah & Eksistensi & Capaian \\
\hline & & R1 = Mentor Role & 28 & 25 & $89,28 \%$ \\
\hline & & R2 = Facilitator Role & 65 & 56 & $86,15 \%$ \\
\hline & & R3 = Monitor Role & 26 & 21 & $80,76 \%$ \\
\hline & & R4 = Co-ordinator Role & 69 & 51 & $73,91 \%$ \\
\hline & & R5 = Director Role & 40 & 22 & $55 \%$ \\
\hline & & R6 = Producer Role & 79 & 65 & $82,27 \%$ \\
\hline & & R7 = Broker Role & 24 & 21 & $87,5 \%$ \\
\hline & & R8 = Innovator & 19 & 17 & $89,47 \%$ \\
\hline & & TOTAL & 350 & 278 & $79,42 \%$ \\
\hline \multicolumn{3}{|c|}{ Capaian Role Keseluruhan } & 970 & 768 & $\mathbf{7 9 , 1 7 \%}$ \\
\hline
\end{tabular}

Sumber : Diolah dari Data Primer Pemetaan Peran Kepemimpinan

Berdasarkan tabel 5.17, dapat dijelaskan bahwa efektifitas dalam menjalankan peran kepemimpinan sebagai kunci kompetensi seorang pemimpin, belum dilaksanakan sepenuhnya atau belum mencapai $100 \%$ oleh masing-masing pemangku jabatan pada bidang/seksi dan bagian/sub bagian yang terkait. Dari 3 Bidang dan 1 Bagian, tingkat efektifitas yang dilaksanakan oleh
Bidang Pelayanan tercapai $84,57 \%$ dengan capaian terendah yaitu terletak pada broker role, Bidang Keperawatan tercapai $88,47 \%$ terletak pada innovator role, Bidang Pengembangan dan Pengaduan tercapai $61,37 \%$ terletak pada facilitator role, Bagian Tata Usaha tercapai $79,42 \%$ terletak pada director role dan tingkat efektifitas pelaksanaan role keseluruhan organisasi mencapai $79,17 \%$.

Tabel 11 Hasil Pengukuran Indeks Kepuasan Masyarakat RSUD dr. R. Soedarsono

\begin{tabular}{|c|c|c|c|c|c|c|c|c|c|}
\hline \multirow{2}{*}{ No } & \multirow{2}{*}{$\begin{array}{l}\text { Variabel yang dinilai sesuai } \\
\text { Persepsi Responden }\end{array}$} & \multicolumn{5}{|c|}{ Jawaban } & \multirow{2}{*}{ JML } & \multirow{2}{*}{ NILAI } & \multirow{2}{*}{$\begin{array}{l}\mathrm{IKM} \\
(\%)\end{array}$} \\
\hline & & 0 & 1 & 2 & 4 & 5 & & & \\
\hline 1 & Kemudahan Prosedur Pelayanan & 0 & 3 & 20 & 75 & 2 & 100 & 353 & 70.60 \\
\hline 2 & $\begin{array}{l}\text { Kesesuaian Persyaratan } \\
\text { Pelayanan dengan Jenis } \\
\text { Pelayanan }\end{array}$ & 2 & 0 & 9 & 89 & 0 & 100 & 374 & 74.80 \\
\hline 3 & $\begin{array}{l}\text { Kejelasan dan Kepastian Petugas } \\
\text { yang Melayani }\end{array}$ & 0 & 0 & 21 & 79 & 0 & 100 & 358 & 71.60 \\
\hline 4 & $\begin{array}{l}\text { Kedisiplinan Petugas dalam } \\
\text { memberikan pelayanan }\end{array}$ & 1 & 1 & 21 & 75 & 2 & 100 & 353 & 70.60 \\
\hline 5 & $\begin{array}{l}\text { Tanggung Jawab Petugas dalam } \\
\text { memberikan pelayanan }\end{array}$ & 0 & 0 & 6 & 93 & 1 & 100 & 389 & 77.80 \\
\hline 6 & $\begin{array}{l}\text { Kemampuan Petugas dalam } \\
\text { memberikan pelayanan }\end{array}$ & 4 & 0 & 6 & 89 & 1 & 100 & 373 & 74.60 \\
\hline
\end{tabular}




\begin{tabular}{|c|c|c|c|c|c|c|c|c|c|}
\hline \multirow{2}{*}{ No } & \multirow{2}{*}{$\begin{array}{l}\text { Variabel yang dinilai sesuai } \\
\text { Persepsi Responden }\end{array}$} & \multicolumn{5}{|c|}{ Jawaban } & \multirow{2}{*}{ JML } & \multirow{2}{*}{ NILAI } & \multirow{2}{*}{$\begin{array}{l}\text { IKM } \\
(\%)\end{array}$} \\
\hline & & 0 & 1 & 2 & 4 & 5 & & & \\
\hline 7 & $\begin{array}{l}\text { Kecepatan dalam memberikan } \\
\text { Pelayanan }\end{array}$ & 1 & 4 & 25 & 70 & 0 & 100 & 334 & 66.80 \\
\hline 8 & $\begin{array}{l}\text { Kemajuan Kesembuhan setelah } \\
\text { berobat }\end{array}$ & 4 & 0 & 13 & 82 & 1 & 100 & 359 & 71.80 \\
\hline 9 & Kualitas Pelayanan Dokter & 0 & 0 & 8 & 91 & 1 & 100 & 385 & 77.00 \\
\hline 10 & $\begin{array}{l}\text { Dokter Memberikan Penjelasan } \\
\text { tentang penyakit / pengobatan }\end{array}$ & 4 & 4 & 9 & 79 & 4 & 100 & 358 & 71.60 \\
\hline 11 & $\begin{array}{l}\text { Kesopanan Dokter selama } \\
\text { melayani }\end{array}$ & 0 & 0 & 4 & 96 & 0 & 100 & 392 & 78.40 \\
\hline 12 & $\begin{array}{l}\text { Keadilan Untuk Mendapatkan } \\
\text { Pelayanan }\end{array}$ & 5 & 2 & 7 & 85 & 1 & 100 & 361 & 72.20 \\
\hline 13 & $\begin{array}{l}\text { Kewajaran Biaya Untuk } \\
\text { Mendapatkan Pelayanan }\end{array}$ & 14 & 0 & 3 & 83 & 0 & 100 & 338 & 67.60 \\
\hline 14 & $\begin{array}{l}\text { Kesesuaian Biaya Antara Biaya } \\
\text { Yang di Bayarkan dengan Biaya } \\
\text { (Tarif) yang di Tetapkan }\end{array}$ & 13 & 0 & 9 & 77 & 1 & 100 & 331 & 66.20 \\
\hline 15 & $\begin{array}{l}\text { Ketepatan Pelaksanaan terhadap } \\
\text { jadwal waktu pelayanan }\end{array}$ & 0 & 2 & 30 & 62 & 6 & 100 & 340 & 68.00 \\
\hline 16 & $\begin{array}{l}\text { Keramahan Petugas dalam } \\
\text { memberikan pelayanan }\end{array}$ & 1 & 1 & 9 & 88 & 1 & 100 & 376 & 75.20 \\
\hline 17 & $\begin{array}{l}\text { Kenyamanan Pelayanan di ruang } \\
\text { pemeriksaan }\end{array}$ & 0 & 3 & 13 & 84 & 0 & 100 & 365 & 73.00 \\
\hline 18 & Kenyamanan Ruang Tunggu & 0 & 5 & 27 & 68 & 0 & 100 & 331 & 66.20 \\
\hline 19 & Keamanan Lingkungan & 2 & 0 & 3 & 95 & 0 & 100 & 386 & 77.20 \\
\hline 20 & $\begin{array}{l}\text { Ketanggapan perawat terhadap } \\
\text { pasien }\end{array}$ & 10 & 0 & 17 & 72 & 1 & 100 & 327 & 65.40 \\
\hline 21 & Kualitas pelayanan perawatan & 1 & 4 & 10 & 85 & 0 & 100 & 364 & 72.80 \\
\hline 22 & Penyuluhan oleh perawat & 4 & 40 & 15 & 40 & 1 & 100 & 235 & 47.00 \\
\hline 23 & $\begin{array}{l}\text { Kesopanan perawat dalam } \\
\text { memberikan asuhan keperawatan }\end{array}$ & 1 & 0 & 7 & 92 & 0 & 100 & 382 & 76.40 \\
\hline 24 & $\begin{array}{l}\text { Respon terhadap tenaga } \\
\text { keperawatan selama menerima } \\
\text { pelayanan }\end{array}$ & 8 & 6 & 10 & 75 & 1 & 100 & 331 & 66.20 \\
\hline & Nilai IKM Agregrat & 75 & 75 & 302 & 1924 & 24 & 2400 & 8495 & 70.79 \\
\hline
\end{tabular}

Sumber : Diolah dari Data Primer Kuesioner Indeks Kepuasan Masyarakat

Indeks Kepuasan Pasien mencapai 70,79\% yang secara keseluruhan dinyatakan baik atau puas, namun ada beberapa variabel yang dinilai rendah dari hasil Indeks Kepuasan Masyarakat agregat yaitu kecepatan dalam memberikan pelayanan, kewajaran biaya untk mendapatkan pelayanan, kesesuaian biaya antara biaya yang dibayarkan dengan biaya (tarif) yang ditetapkan, ketepatan pelaksanaan jadwal waktu pelayanan, kenyamaan ruang tunggu, ketaggapan perawat terhadap pasien, penyuluhan perawat dan respon terhadap tenaga keperawatan selama menerima pelayanan. 
Tabel 12 Hasil Pengukuran Indeks Kepuasan Karyawan RSUD dr. R. Soedarsono

\begin{tabular}{|c|c|c|c|c|c|c|c|c|c|}
\hline \multirow{2}{*}{ No } & \multirow{2}{*}{$\begin{array}{l}\text { Variabel yang dinilai sesuai } \\
\text { Persepsi Responden }\end{array}$} & \multicolumn{6}{|c|}{ Jml. Responden/Skor } & \multirow{2}{*}{ NILAI } & \multirow{2}{*}{$\begin{array}{l}\text { IKK } \\
(\%)\end{array}$} \\
\hline & & 0 & 1 & 2 & 4 & 5 & JML & & \\
\hline 1 & Kenyamanan Ruang Kerja & 1 & 3 & 27 & 18 & 2 & 51 & 139 & 54.51 \\
\hline 2 & $\begin{array}{l}\text { Akses Informasi (Kebijakan, } \\
\text { Keuangan, dan Kesejahteraan) }\end{array}$ & 0 & 10 & 23 & 16 & 2 & 51 & 130 & 50.98 \\
\hline 3 & $\begin{array}{l}\text { Arahan Kebijakan direktur } \\
\text { untuk akses dan mutu }\end{array}$ & 1 & 7 & 27 & 14 & 2 & 51 & 127 & 49.80 \\
\hline 4 & $\begin{array}{l}\text { Kesempatan pengembangan } \\
\text { karir }\end{array}$ & 0 & 7 & 27 & 12 & 5 & 51 & 134 & 52.55 \\
\hline 5 & $\begin{array}{l}\text { ketersediaan Peralatan kerja } \\
\text { (Peralatan Medik) }\end{array}$ & 12 & 4 & 12 & 20 & 3 & 51 & 123 & 48.24 \\
\hline 6 & $\begin{array}{l}\text { ketersediaan Peralatan kerja } \\
\text { (Kebidanan / Keperawatan) }\end{array}$ & 17 & 0 & 9 & 21 & 4 & 51 & 122 & 47.84 \\
\hline 7 & $\begin{array}{l}\text { ketersediaan Peralatan kerja } \\
\text { (Lab/rad/elektro) }\end{array}$ & 15 & 0 & 12 & 21 & 3 & 51 & 123 & 48.24 \\
\hline 8 & $\begin{array}{l}\text { ketersediaan Peralatan kerja } \\
\text { kantor / computer }\end{array}$ & 7 & 3 & 16 & 23 & 2 & 51 & 137 & 53.73 \\
\hline 9 & $\begin{array}{l}\text { Ketersediaan alat pelindung } \\
\text { diri }\end{array}$ & 4 & 6 & 23 & 15 & 3 & 51 & 127 & 49.80 \\
\hline 10 & $\begin{array}{l}\text { Iklim Kerja dan Hubungan } \\
\text { Kerja Antar Pimpinan }\end{array}$ & 0 & 7 & 16 & 27 & 1 & 51 & 152 & 59.61 \\
\hline 11 & $\begin{array}{l}\text { Kerjasama Antara staf medik, } \\
\text { dengan staf keperawatan }\end{array}$ & 5 & 2 & 13 & 29 & 2 & 51 & 154 & 60.39 \\
\hline 12 & $\begin{array}{l}\text { Tingkat Kepatuhan } \\
\text { Protap/SOP Tenaga Medis }\end{array}$ & 11 & 1 & 10 & 27 & 2 & 51 & 139 & 54.51 \\
\hline 13 & $\begin{array}{l}\text { Tingkat Kepatuhan } \\
\text { Protap/SOP Tenaga } \\
\text { Perawat/Bidan }\end{array}$ & 13 & 1 & 7 & 29 & 1 & 51 & 136 & 53.33 \\
\hline 14 & $\begin{array}{l}\text { Tingkat Kepatuhan } \\
\text { Protap/SOP Nakes Lain }\end{array}$ & 11 & 2 & 13 & 21 & 4 & 51 & 132 & 51.76 \\
\hline 15 & $\begin{array}{l}\text { Kualitas Supervisi Pelayanan } \\
\text { Oleh Pejabat Struktural }\end{array}$ & 2 & 5 & 22 & 21 & 1 & 51 & 138 & 54.12 \\
\hline 16 & $\begin{array}{l}\text { Akses Karyawan untuk } \\
\text { Menghubungi, konsul, } \\
\text { bertemu dengan Direktur }\end{array}$ & 1 & 4 & 15 & 27 & 4 & 51 & 162 & 63.53 \\
\hline 17 & $\begin{array}{l}\text { Akses Karyawan untuk } \\
\text { Menghubungi, konsul, } \\
\text { bertemu dengan Pejabat } \\
\text { Struktural }\end{array}$ & 4 & 2 & 11 & 31 & 3 & 51 & 163 & 63.92 \\
\hline 18 & $\begin{array}{l}\text { Akses Karyawan untuk } \\
\text { Menghubungi, konsul, } \\
\text { bertemu dengan Pimpinan } \\
\text { Instalasi Pelayanan }\end{array}$ & 5 & 1 & 6 & 32 & 7 & 51 & 176 & 69.02 \\
\hline 19 & $\begin{array}{l}\text { Akses Karyawan untuk } \\
\text { Menghubungi, konsul, } \\
\text { bertemu dengan Kepala }\end{array}$ & 6 & 0 & 5 & 37 & 3 & 51 & 173 & 67.84 \\
\hline
\end{tabular}




\begin{tabular}{|c|c|c|c|c|c|c|c|c|c|}
\hline \multirow{2}{*}{ No } & \multirow{2}{*}{$\begin{array}{l}\text { Variabel yang dinilai sesuai } \\
\text { Persepsi Responden }\end{array}$} & \multicolumn{6}{|c|}{ Jml. Responden/Skor } & \multirow{2}{*}{ NILAI } & \multirow{2}{*}{$\begin{array}{l}\text { IKK } \\
(\%)\end{array}$} \\
\hline & & 0 & 1 & 2 & 4 & 5 & JML & & \\
\hline & Poliklinik/Kepala Ruangan & & & & & & & & \\
\hline 20 & $\begin{array}{l}\text { Akses Karyawan untuk } \\
\text { Menghubungi, konsul, } \\
\text { bertemu dengan Dokter } \\
\text { (DPJP) yang merawat pasien }\end{array}$ & 8 & 2 & 9 & 27 & 5 & 51 & 153 & 60.00 \\
\hline 21 & Pembagian Jasa Pelayanan & 7 & 15 & 16 & 12 & 1 & 51 & 100 & 39.22 \\
\hline 22 & Pembinaan Keagamaan & 3 & 16 & 17 & 14 & 1 & 51 & 111 & 43.53 \\
\hline 23 & $\begin{array}{l}\text { Sosialisasi/Desiminasi } \\
\text { Peraturan Baru/Kebijakan } \\
\text { yang harus diketahui oleh } \\
\text { seluruh karyawan }\end{array}$ & 2 & 13 & 25 & 10 & 1 & 51 & 108 & 42.35 \\
\hline 24 & $\begin{array}{l}\text { Acara Bersama Keluarga } \\
\text { Karyawan (Family Gathering) }\end{array}$ & 2 & 22 & 18 & 8 & 1 & 51 & 95 & 37.25 \\
\hline & IKK AGREGAT & 137 & 133 & 379 & 512 & 63 & 1224 & 3254 & 53.17 \\
\hline
\end{tabular}

Sumber: Diolah dari Data Primer Kuesioner Indeks Kepuasan Masyarakat

Indeks Kepuasan Karyawan mencapai $53,17 \%$ yang secara keseluruhan dinyatakan tidak puas dengan variabel terendah yaitu akses informasi (kebijakan, keuangan, dan kesejahteraan), kesempatan pengembangan karir, ketersediaan peralatan kerja (peralatan medik), ketersediaan Peralatan kerja (Kebidanan / Keperawatan), ketersediaan Peralatan kerja (Lab/rad/elektro), Ketersediaan alat pelindung diri, Pembagian Jasa Pelayanan, Pembinaan Keagamaan, Sosialisasi/ Desiminasi Peraturan Baru/Kebijakan yang harus diketahui oleh seluruh karyawan, dan Acara Bersama Keluarga Karyawan (Family Gathering).

\section{PEMBAHASAN}

Menurut Undang-Undang Republik Indonesia Nomor 5 Tahun 2014 Tentang Aparatur Sipil Negara Pasal 90, batas usia pensiun PNS 58 (lima puluh delapan) tahun bagi Pejabat Administrasi. Pasal 13, Pasal 14, dan Pasal 19 Undang-Undang Nomor 5 Tahun 2014 tentang Aparatur Sipil Negara menentukan bahwa Jabatan Administrasi terdiri atas: a) Jabatan Administrator; b) Jabatan Pengawas; dan c) Jabatan Pelaksana. Dalam Pasal 131 Undang-Undang Nomor 5 Tahun 2014 tentang Aparatur Sipil Negara jabatan
Eselon III setara dengan Jabatan Administrator; jabatan Eselon IV setara dengan Jabatan Pengawas.

Dengan demikian identitas responden yang mendekati batas usia pensiun ada 11 orang yaitu 4 orang dari pejabat Eselon III dan 7 orang lainnya dari pejabat Eselon IV dan 2 orang lainnya masih jauh dari batas usia pensiun.

Berdasarkan lama bekerja di bidangnya, responden dalam penelitian ini dapat didiskripsikan bahwa responden pada Eselon III yang bekerja selama 1-5 tahun sebanyak 4 orang atau 100\%, pada Eselon IV sebanyak 7 orang atau $77,8 \%$, yang bekerja selama 7 tahun sebanyak 2 orang $22,2 \%$ terdapat pada pejabat Eselon IV. Artinya, pejabat struktural pada tingkat Eselon IV yang terdiri dari hanya 2 orang kemungkinan yang lebih berpengalaman di bidangnya.

Komitmen Afektif pada Eselon IV dan Eselon III sama-sama termasuk dalam kategori cukup tinggi, komitmen berkelanjutan rendah dan komitmen normatif untuk Eselon III dalam kategori rendah untuk Eselon IV dalam kategori cukup tinggi. Sehingga, dapat disimpulkan bahwa komitmen organisasi pada tingkat Eselon III termasuk dalam kategori rendah, pada tingkat Eselon IV termasuk 
dalam kategori cukup tinggi dimana ini berarti kesediaan pejabat struktural untuk tetap bertahan dalam organisasi hanya terdapat pada pejabat Eselon IV karena tingkat kepatuhan terhadap aturan-aturan organisasi lebih tinggi.

Komitmen Bidang Pelayanan, Bidang Keperawatan, Bidang Pengembangan dan Pengaduan, Bagian Tata Usaha memiliki komitmen afektif dengan kategori cukup tinggi, komitmen berkelanjutan yang rendah dan komitmen normatif yang cukup tinggi. Dengan demikian hasil akumulasi keseluruhan kesediaan untuk bertahan di organisasi hanya dirasakan oleh bidang pelayanan dengan kategori yang cukup tinggi karena ada kemungkinan beberapa tugas pokok dan fungsi yang harusnya dilaksanakan oleh bidang/bagian tertentu dilaksanakan oleh bidang pelayanan sehingga bidang pelayanan merasa bertanggung jawab dan memiliki tingkat kepatuhan yang tinggi.

Kinerja manajerial dilihat dari peran dan aktifitas yang dilaksanakan oleh pejabat struktural serta dilihat dari hasil pengukuran indeks kepuasan masyarakat dan indeks kepuasan karyawan. Aktivitas yang dilaksanakan pejabat struktural berdasarkan tugas pokok dan fungsi pada Eselon III mencapai $79,05 \%$ yang kemungkinan disebabkan oleh komitmen untuk bertahan memang didasari keinginannya sendiri, bukan karena tidak adanya pilihan kerja di tempat lain maupun rasa tanggung jawab terhadap organisasi, melainkan kedekatan antar rekan kerja yang kemudian menciptakan keterikatan emosional karena setuju dan mempercayai misi, tujuan dan nilai-nilai organisasi yang dijalankan. Sehingga, pejabat struktural Eselon III lebih mementingkan pekerjaan diluar daripada pekerjaan yang di emban sekarang karena kemungkinan memiliki pekerjaan lain diluar organisasi yang disebabkan oleh komitmen berkelanjutan yang rendah.

Pada Eselon IV dengan komitmen yang memiliki penghayatan yang positif terhadap organisasi dan dapat dengan mudah menerima aturan dan kebijakan organisasi. Bagi responden fasilitas dan kesejahteraan bukan alasan utama mereka bekerja di RSUD dr. R. Soedarsono. Eselon IV juga merasakan adanya suatu kewajiban dan tugas untuk bertahan dalam organisasi dan memiliki kecenderungan untuk mematuhi peraturan yang ada, akan merasa bersalah bila melanggar aturan karena tidak ingin memberikan dampak yang buruk bagi organisasi. Menurut penelitian terdahulu, profil ini merupakan profil komitmen organisasi yang ideal bagi organisasi. Namun, pencapaian efektifitas pelaksanaan tugas pokok dan fungsi hanya sebesar 79,77\%. Ketidaksinkronan ini kemungkinan bisa terjadi karena pengisian kuesioner untuk mengukur komitmen tidak sesuai dengan apa yang dirasakan sebenarnya.

Pada tingkat akumulasi per bidang dan bagian, Bidang Pelayanan memiliki komitmen terhadap organisasi yang cukup tinggi dengan tingkat efektifitas yang dihasilkan mencapai $86,73 \%$ sedangkan Bidang Keperawatan, Bidang Pengembangan dan Pengaduan serta Bagian Tata Usaha memiliki komitmen yang rendah dengan pencapain tingkat efektifitas masing-masing sebesar $88,09 \%$, 60,67\%, 78,67\%. Komitmen untuk kesediaan bertahan pada organisasi hanya dirasakan oleh bidang pelayanan karena bidang pelayanan merasa bertanggung jawab dan beberapa tugas pokok dan fungsi yang harusnya dilaksanakan oleh bidang/bagian tertentu dilaksanakan oleh bidang pelayanan serta tingkat efektifitasnya lebih tinggi dari bidang/bagian lain meskipun belum mencapai $100 \%$ sedangkan komitmen dari 2 bidang 1 bagian lainnya memiliki komitmen yang rendah, tetapi hasil akumulasi keseluruhan unsur pejabat menunjukkan komitmen yang rendah terhadap organisasi dan tingkat keseluruhan organisasi yang dicapai sebesar 79,48\%, dilihat dari aktifitas berdasarkan tugas pokok dan fungsi yang seharusnya dikerjakan oleh bidang/bagian 
tersebut dilakukan oleh bidang/bagian lain sehingga tingkat efektifitas pelaksanaan tugas pokok dan fungsi belum mencapai $100 \%$ serta bidang/bagian tersebut belum melaksanakan tugas pokok dan fungsi masing-masing yang seharusnya dilaksanakan oleh bidang/bagian itu sendiri.

Aktivitas yang dilaksanakan berdasarkan tugas pokok dan fungsi tersebut di petakan kedalam 8 leadership role yaitu mentor role, facilitator role, monitor role, coordinator role, director role, producer role, broker role, innovator role (Quinn's, 1996) untuk mengetahui seberapa efektif kah seorang pejabat struktural pada tingkat Eselon III dan Eselon IV melaksanakan perannya sebagai seorang pemimpin. Pada Eselon III tingkat efektifitas pelaksanaan leadership role mencapai $76,84 \%$, pada Eselon IV mencapai $80,76 \%$. Dimana pejabat struktural Eselon III dan Eselon IV belum sepenuhnya melakukan tugas pokok dan fungsi serta peran sebagai seorang pemimpin yang berkompeten, sedangkan kemampuan yang dibutuhkan seorang pemimpin adalah menggerakkan sumber daya organisasi terutama dalam pengelolaan sumber daya manusia yang sangat menentukan kelangsungan hidup suatu organisasi dalam rangka pencapaian tujuan yang telah ditetapkan. Begitupun juga dengan bidang pelayanan mencapai $84,57 \%$, Bidang Keperawatan mencapai $88,47 \%$, Bidang Pengembangan dan Pengaduan mencapai $61,37 \%$, Bidang Tata Usaha mencapai 79,42\%. Maka, tujuan yang telah ditetapkan sebagai hasil kinerja kepemimpinan yang di ukur dari outcome oleh organisasi belum dapat tercapai secara maksimal. Tujuan yang ditetapkan oleh organisasi adalah dapat dilihat dari Indeks Kepuasaan Masyarakat yang mencapai 70,79\%, Indek Kepuasan Karyawan mencapai 53,17\%. Masyarakat merasa puas terhadap pelayanan yang diberikan oleh rumah sakit namun karyawan merasa sebaliknya, ini bisa terjadi kemungkinan masyarakat tidak memiliki pilihan lain selain RSUD Dr. R. Soedarsono yang merupakan akses terdekat untuk menerima pelayanan kesehatan yang lebih komprehensif.

\section{SIMPULAN}

Penelitian yang dilakukan ini bertujuan untuk menganalisis aspek komitmen kepemimpinan terhadap tingkat efektifitas organisasi dan menganilisis aspek kinerja kepemimpinan pejabat struktural. Maka kesimpulan yang dapat dikemukakan dalam penelitian ini adalah sebagai berikut:

1. Komitmen afektif, komitmen kelanjutan dan komitmen normatif pada Eselon III dan Eselon IV memiliki tingkatan yang berbeda. Pada Eselon III menunjukkan bahwa komitmen untuk tetap bertahan di organisasi ada kemungkinan bukan karena tidak adanya pekerjaan di tempat lain maupun rasa tanggung jawab terhadap organisasi melainkan faktor lain Namun, pada Eselon IV menunjukkan komitmen yang ideal bagi organisasi karena bekerja dengan tulus tanpa memperhitungkan keuntungan atau kerugian dalam bertahan dalam organisasi dan lebih mentaati aturanaturan yang ada di organisasi.

2. Komitmen dari 3 bidang 1 bagian, dapat disimpulkan bahwa kesediaan untuk bertahan dalam organisasi hanya dirasakan oleh Bidang Pelayanan, sedangkan 2 bidang 1 bagian lainnya dalam kategori yang rendah. Bidang Pelayanan merasa bertanggung jawab dan memiliki tingkat kepatuhan yang tinggi ada kemungkinan disebabkan karena beberapa tugas pokok dan fungsi yang harusnya dilaksanakan oleh bidang/bagian tertentu dilaksanakan bidang pelayanan.

3. Komitmen secara keseluruhan pejabat struktural di RSUD dr. R. Soedarsono terhadap organisasi berada pada kategori yang rendah.

4. Kinerja pejabat struktural masih belum mencapai $100 \%$ karena peran dan aktivitasnya menurut tugas pokok dan 
fungsi yang di emban, belum sepenuhnya dilaksanakan. Kemungkinan dikarenakan pejabat struktural kurang memahami tugas pokok dan fungsi di emban masingmasing. Sehingga, tugas pokok dan fungsi yang seharusnya dilaksanakan oleh suatu bidang/bagian, dilaksanakan oleh bidang/bagian lain. Hasil Kinerja pejabat struktural juga bisa dilihat dari pencapaian indeks kepuasan masyarakat yang didapati sebesar $70,79 \%$ dan indeks kepuasan karyawan sebesar $53,17 \%$.

Tingkat efektifitas per eselon organisasi belum mencapai $100 \%$, ada kemungkinan karena tidak adanya komitmen untuk bersama-sama mencapai tujuan bersama serta tugas pokok dan fungsi yang harus dilaksanakan oleh bidang/bagian tersebut dilakukan oleh bidang/bagian lain.

\section{SARAN}

1. Bagi RSUD dr. R. Soedarsono

a. Meningkatkan fasilitas untuk menumbuhkan komitmen serta kelangsungan organisasi yaitu diantaranya akses untuk memperoleh informasi mengenai kebijakan, keuangan dan kesejahteraan, arahan kebijakan direktur untuk akses dan mutu, kesempatan pengembangan karir, ketersediaan peralatan kerja, ketersediaan alat pelindung diri, pembagian jasa pelayanan, pembinaan keagamaan, sosialisasi mengenai peraturan baru/kebijakan, acara bersama keluarga (Family Gathering).

b. Memahami tugas pokok dan fungsi yang di emban masing-masing pejabat struktural sesuai dengan Peraturan Walikota Nomor 73 Tahun 2011 Tentang Tugas Pokok Dan Fungsi Rumah Sakit Umum Daerah dr. R. Soedarsono agar tidak terjadi gap antara bidang/bagian yang satu dengan yang lain.

c. Memahami peran sebagai pemimpin yang berkompeten dalam menggerakkan sumber daya untuk mencapai tujuan organisasi.

2. Bagi Peneliti lain, bisa menggunakan penelitian yang sejenis namun secara mendalam dengan melakukan uji statistik hubungan atau pengaruh dari beberapa variabel.

\section{DAFTAR PUSTAKA}

Amirullah. 2015. Kepemimpinan dan Kerja Sama Tim. Mitra Wacana Medika. Jakarta.

Arifin, Syamsul. 2012. Leadership Ilmu dan Seni Kepemimpinan. Mitra Wacana Medika. Jakarta.

Borkowski, Nancy. 2011. Manajemen Pelayanan Kesehatan: Perilaku Organisasi. Edisi 2. Buku Kedokteran EGC. Jakarta.

Denison, Daniel R.1990. Corporate Culture and Organizational Effectiveness. NY. John Willey \& Sons.

Fahmi, Irham. 2016. Pengantar Manajemen Sumber Daya Manusia Konsep dan Kinerja. Edisi Pertama. Mitra Wacana Media. Jakarta

G. Northouse, Peter. 2013. Kepemimpinan: Teori dan Praktik. Edisi Keenam. Cetakan I. PT Indeks. Jakarta.

Kasmir, 2016. Manajemen Sumber Daya Manusia (Teori dan Praktik). Edisi Kesatu. Cetakan Kesatu. Grafindo Persada. Jakarta.

Kaswan, 2012. Manajemen Sumber Daya Manusia Untuk Keunggulan Bersaing Organisasi. Graha Ilmu. Yogyakarta.

Kusdi. 2011. Budaya Organisasi. Teori Penelitian dan Praktik. Salemba Empat. Jakarta.

L. Hughes, Robert C. dkk. 2015. Leadership: Memperkaya Pelajaran dari Pengalaman. Edisi 7. Salemba Humanika. Jakarta 
Meyer, J.F., Natalie, J.Allen., \& Catherine A.Smith, 1993. Commitment to Organization and Occupation Extension and Test of Three Component Conceptualization. Journal of Applied Psychology Vol 78, No. 4, pp. $538-551$.

Mondy, R. Wayne. 2008. Manajemen Sumber Daya Manusia. Erlangga. Jakarta.

Muninjaya, A. A. Gde. 2004. Manajemen Kesehatan. Edisi 2. Buku Kedokteran EGC. Jakarta.

Nawawi, Ismail. 2013. Budaya Organisasi Kepemimpinan dan Kinerja. Edisi Pertama. Kencana Prenadamedia Group. Jakarta.

Parinding, Roberto, 2015. Analisis Pengaruh Komitmen Afektif, Komitmen Berkelanjutan, dan Komitmen Normatif Terhadap Kinerja Karyawan Pada PT. Pegadaian (PERSERO) Cabang Ketapang. Tesis. Fakultas Ekonomi dan Bisnis, Universitas Narotama Surabaya.

Peraturan Presiden Republik Indonesia Nomer 29 Tahun 2014 Sistem Akuntabilitas Kinerja Instansi Pemerintah. 21 April 2014. Lembar Negara Republik Indonesia Tahun 2014 Nomer 80. Jakarta.

Peraturan Walikota Nomor 73 Tahun 2011 Tugas Pokok Dan Fungsi Rumah Sakit Umum Daerah $d r . \quad R$. Soedarsono. 28 Desember 2011. Berita Daerah Kota Pasuruan Tahun 2011 Nomor 68. Pasuruan.

Robbins, Stephen P. 1994. Teori Organisasi: Konsep, Struktur, Proses. P.enerbit Arcan. Jakarta.

Robbins, Stephen P. 1996. Perilaku Organisasi : Konsep, Kontroversi, aplikasi, Prenhallind. Jakarta.

Sandjaya, Ovie Prischilia. 2016. Kajian Manajemen Bidang Keperawatan RSUD dr. R. Soedarsono Kota Pasuruan. Surabaya.
Sembiring, Masana. 2012. Budaya dan Kinerja Organisasi (Perspektif Organisasi Pemerintah). Cetakan Pertama. Fokusmedia. Bandung.

Sugiyono. 2011. Statistika untuk Penelitian. Cetakan Ke-19. Alfabeta. Bandung.

Sugiyono. 2012. Metode Penelitian Kuantitatif,Kualitatif Dan $R \& D$. Cetakan Ke-17. Alfabeta. Bandung.

Tjiharjadi, Semuil. 2012. To Be A Great Effective Leader. Edisi Kesatu. Andi. Yogyakarta.

Ulum, Ihyaul. 2009. Audit Sektor Publik Suatu Pengantar. Penerbit Bumi Aksara. Jakarta.

Undang-undang Republik Indonesia Nomor 44 Tahun 2009 Rumah Sakit. 28 Oktober 2009. Lembaran Negara Republik Indonesia Tahun 2009 Nomor 153. Jakarta.

Undang-Undang Republik Indonesia Nomor 5 Tahun 2014 Tentang Aparatur Sipil Negara. 